\title{
Visual presentation of stimuli in immediate memory'
}

ROBERT G. CROWDER

YALE UNIVERSITY

Simultaneous (SM) and sequential (SQ) visual presentation of consonant series varying in length were compared as a function of stimulus duration and presentation rate, respectively. A systematic dependence of recall upon these parameters was demonstrated for two measures of performance. Second for second, SM presentation was found to be more efficient than $S Q$.

There is an inherent futility in comparing the absolute levels of performance found with different modes of presenting alphanumeric stimuli for immediate recall. The spoken letter, for example, differs so fundamentally from the seen letter that choice of presentation parameters to permit a "fair" comparison is nearly impossible. Likewise there is no standard logic for deciding how long to expose a simultaneously presented (SM) visual series to render it comparable to a sequentially. presented (SQ) series because the former method allows $S$ to scan the stimulus at his own rate and according to his own priorities. On the other hand, variation in mode of presentation can be a useful methodological tool in illuminating effects of other independent variables, such as vocabulary size (Conrad \& Hille, 1957) or acoustic similarity (Conrad, Baddeley, \& Hull, 1966). In preparing a study comparing intraserial repetition effects in SM and SQ visual presentation, the writer was concerned to choose parameters of each yielding generally comparable levels of recall, thus allowing equally for effects of the independent variable. Accordingly, the present study was undertaken to provide parametric data on immediate recall for consonant series as a function of stimulus length, SM or SQ visual presentation, stimulus duration in the case of SM, and presentation rate in the case of SQ. Method

Fifteen Yale undergraduates served in two parts of the experiment, the first devoted to SM presentation and the second to SQ. There were 15 conditions of SM, as determined by orthogonal variation in stimulus length $(6,8$, or 10 consonants) and exposure duration $(1,3,5,7$, or 9 sec.). Each $S$ contributed three replications of this design, yielding a total of 45 observations per data point. The 45 stimuli were presented in a fixed order, with the three stimulus lengths randomized against trials. However, each stimulus was equally often presented at each exposure duration across Ss. Thus stimuli were completely confounded with trials and, of course, with length, but completely balanced with respect to exposure duration and sequence of exposure durations. The 15 conditions of SQ presenta- tion in the second part of the experiment were determined by orthogonal variation in stimulus length $(6,7$, 8,9 , or 10 consonants) and in presentation rate $(2 / \mathrm{sec}$., $1 /$ sec., or $1 / 2$ sec.). Each of the same 15 Ss saw two instances of each treatment combination, yielding 30 observations per data point. As with the SM sub-experiment, a fixed list was used, with balanced assignment of rates to stimuli across different Ss.

Stimuli were developed from a vocabulary of 12 consonants (C, G, H, J, K, L, M, Q, R, S, T, \& X) and ordered such that within adjacent blocks of 12 items there was no repetition of bigrams and no recurrence of a letter in the same serial position. All materials were presented by a Graflex Compact filmstrip projector, with stimuli typed directly on a semi-opaque filmstrip base. The $\mathrm{E}$ controlled duration of SM presentation with a metronome while SQ presentation was governed by a variable-interval timer. Change times between frames of the filmstrip were negligible and thus presentation rates accurately reflected time $\mathrm{S}$ had with each stimulus element. Following presentation of each stimulus, S was allowed $30 \mathrm{sec}$. for ordered, written recall, using a new $3 \times 5$ card for each stimulus.

\section{Results and Discussion}

In Table 1 are displayed the results of both parts of the experiment, expressed in terms of two performance

Table 1. Mean recall performance as a function of scoring method, presentation mode, presentation rate, and stimulus length

\begin{tabular}{|c|c|c|c|c|c|c|}
\hline \multicolumn{7}{|c|}{ Simultaneous Presentation } \\
\hline \multirow{2}{*}{$\begin{array}{l}\text { Stimulus } \\
\text { Length }\end{array}$} & & \multicolumn{5}{|c|}{ Stimulus Duration (sec.) } \\
\hline & & 1 & 3 & 5 & 7 & 9 \\
\hline \multirow[t]{2}{*}{6} & $\operatorname{Pr}(C)$ & .489 & .800 & .867 & .844 & .956 \\
\hline & & .778 & .944 & .961 & .972 & 1.000 \\
\hline \multirow[t]{2}{*}{8} & $\operatorname{Pr}(\mathrm{C})$ & .067 & .178 & .356 & .444 & .578 \\
\hline & & .460 & .694 & .753 & .829 & 949 \\
\hline \multirow[t]{2}{*}{10} & $\operatorname{Pr}(C)$ & .000 & .022 & .000 & .044 & .111 \\
\hline & $p$ & .213 & .387 & .406 & .602 & .629 \\
\hline \multicolumn{7}{|c|}{ Sequential Presentation } \\
\hline \multirow{2}{*}{$\begin{array}{l}\text { Stimulus } \\
\text { Length }\end{array}$} & & \multicolumn{4}{|c|}{ Presentation Rate (Cons./sec.) } & \\
\hline & & $2 / \sec$ & & $1 / \sec$. & & $1 / 2$ sec. \\
\hline \multirow[t]{2}{*}{6} & $\operatorname{Pr}(C)$ & .433 & & .667 & & .767 \\
\hline & $\mathrm{P}$ & .829 & & .876 & & .962 \\
\hline \multirow[t]{2}{*}{7} & $\operatorname{Pr}(C)$ & .133 & & .367 & & .567 \\
\hline & $p$ & .732 & & .757 & & .900 \\
\hline \multirow[t]{2}{*}{8} & $\operatorname{Pr}(\mathrm{C})$ & .100 & & .200 & & .267 \\
\hline & $\mathrm{p}$ & .479 & & .658 & & .687 \\
\hline \multirow[t]{2}{*}{9} & $\operatorname{Pr}(C)$ & .066 & & .000 & & .200 \\
\hline & & .460 & & .567 & & .597 \\
\hline \multirow[t]{2}{*}{10} & $\operatorname{Pr}(C)$ & .033 & & .000 & & .167 \\
\hline & $\mathbf{p}$ & .321 & & .540 & & .584 \\
\hline
\end{tabular}


measures. Rows labelled $\operatorname{Pr}(C)$ present mean proportions of stimuli recalled perfectly; rows labelled $P$ give an index based on Kendall's P (Kendall, 1955). The latter is calculated as the proportion of ordered pairs in the stimulus which are preserved in the response (e.g., 15 possible for a 6-element item, 28 for an 8-element item). The $\mathbf{P}$ index jointly covers retention of the stimulus elements and of their order, failing to detect only errors of adding an extra letter to a series.

The Pearson correlation between proportion correct and $\mathrm{P}$ for the 30 treatment combinations of both parts of the study was .903 , indicating a generally high level of agreement. However, inspection of Table 1 suggests that $\mathrm{P}$ may be the more useful of the two measures. For example, all reversals apparent among the data based on completely correct responses are "corrected" in the $\mathbf{P}$ data, viz., recall of SM 6-consonant series at 5 and 7 sec., recall of SM 10-consonant series at 3 and 5 sec., and recall of 9- and 10-consonant SQ series at $2 / \mathrm{sec}$. and $1 / \mathrm{sec}$. rates.

The effects of the presentation parameters studied were orderly and may be summarized as follows: (a) Stimulus length was inversely related to recall under all conditions of presentation. (b) Recall of SM series was directly related to study time. (c) Recall of SQ series was inversely related to presentation speed. Although the obtained superiority of slow over fast $S Q$ rates has not been a universal finding (Posner, 1963), it is consistent with the majority of recent reports (e.g., Murray, 1965; Norman, 1966) and presumably reflects variation in time for $S$ to rehearse and/or organize the material being presented to him.

A comparison of values for SM and SQ procedures in Table 1 suggests that Ss' time is better invested in a given amount of SM presentation than in an equal period of time divided into successive intervals of SQ presentation. Apparently in SM procedures, $S$ does not pace himself metronomically to encode each stimulus element in order. He may, instead, encode the material in bigram or trigram groups, with perhaps even selective attention to disadvantageous serial positions. Mayzner \& Adler (1965) have shown that under certain conditions grouping series of homogeneous elements leads to improved recall. Naturally, the present data are limited in generality to the exact conditions of this experiment with respect to S population, stimulus vocabulary, legibility and conspicuity furnished by the presentation device, and recall modes. It is hoped, however, that these data imply certain equivalence relations among different methods and rates of presentation which will prove of wider generality.

\section{References}

Conrad, R., Baddeley, A. D., \& Hull, A. J. Rate of presentation and the acoustic similarity effect in short-term memory. Psychon. Sci., 1966, 5, 233-234.

Conrad, R., \& Hille, B. A. Memory for long telephone numbers. Post Office Telecomm. J., 1957, 10, 37-39.

Kendall, M. G. Rank Correlation Methods (Ed. 2). London: Griffin, 1955.

Mayzner, M. S., \& Adler, S. A further study of information "chunking" and short-term retention. J. Psychol., 1965, 59, 125-130.

Murray, D. J. Vocalization-at-presentation and immediate recall with varying presentation rates. Quart. J. exp. Psychol., 1965, 17, 47-56.

Noman, D. A. Acquisition and retention in short-term memory. $J$. exp. Psychol., 1966, 72, 369-381.

Posner, M. I. Immediate memory in sequential tasks. Psychol. Bull., 1963, 60, 333-349.

\section{Note}

1. This research was supported in part by NSF Grant GB 4066 . 